\title{
The genetics of type 2 diabetes
}

\author{
Mark McCarthy' \& Stephan Menzel ${ }^{2}$ \\ ${ }^{1}$ Genetics and Genomics Research Institute, Imperial College School of Medicine and MRC-Clinical Sciences Centre, Hammersmith Hospital, \\ Du Cane Road, London, W12 ONN and ${ }^{2}$ Wellcome Trust Centre for Human Genetics, Roosevelt Drive, Oxford, OX3 7BN, UK
}

Keywords: complex traits, diabetes, gene identification, insulin action, insulin secretion

\section{Introduction}

Of the various subtypes of diabetes, type 2 diabetes has the greatest impact on health worldwide. Around 150 million people have type 2 diabetes, and the prevalence will rise by $40 \%$ by 2010 [1]. Type 2 diabetes and its complications already consume $5-10 \%$ of health budgets in many countries [2]. Yet, despite the manifest importance of this condition, and many years of detailed metabolic study, understanding of the basic aetiological mechanisms remains fragmentary [3]. This contrasts with the other major subtype of diabetes, type 1, where it is wellestablished that the major aetiological process involves autoimmune destruction of the insulin-secreting pancreatic beta-cells. Type 2 diabetes displays a clear association with obesity, and the clustering of type 2 diabetes, hypertension, dyslipidaemia and macrovascular disease within individuals and families, indicates that reduced sensitivity to the peripheral actions of insulin (i.e. insulin resistance) plays a key role in disease pathogenesis [4]. However, since many individuals with marked insulin resistance still manage to maintain normal glucose homeostasis, variation in the compensatory capacity of the pancreatic beta-cell must be an equal partner in disease progression [5]. Efforts to characterize further the crucial intermediate metabolic steps in the development of full-blown type 2 diabetes have largely foundered on the rocks of individual heterogeneity and the complicating effects of hyperglycaemia (and its treatment) on the very intermediate traits that investigators might wish to measure.

Improved glycaemic control has been clearly shown to reduce the burden of diabetic complications [6]. Since currently available treatments rarely achieve the goal of lifelong restoration of normoglycaemia, there is manifest need for improved therapeutic and preventative modalities targeted to the key pathogenetic steps. As with the other complex inherited traits, the hope is that genetic analyses

Correspondence: Professor M. McCarthy, Genetics and Genomics Research Institute, Imperial College School of Medicine and MRC-Clinical Sciences Centre, Hammersmith Hospital, Du Cane Road, London, WI2 0NN. Tel.: + 4420 7886I235; Fax: + 4420 7886I790; E-mail: m.mccarthy@ic.ac.uk

Received 27 March 2000, accepted 14 November 2000. will deliver the molecular understanding that will inform future drug development.

\section{Nature and nurture}

The earliest evidence for a major genetic contribution to the development of type 2 diabetes came from classical experimental paradigms including twin, family and population studies. These clearly demonstrate that the closer the genetic relationship between two individuals, the more likely they are to share the same glucose tolerance status. Thus, identical twin pairs show a higher concordance rate for diabetes than do fraternal twins [7, 8] and first-degree relatives of diabetic individuals have lifetime rates of diabetes up to four times the background population prevalence [9]. Marked differences in diabetes prevalence between distinct ethnic groups living in adjacent, similar environments (as a result of cultural isolation and/or migration) provide additional evidence for genetic effects [10]: in some instances, the risk of diabetes is clearly related to the relative proportions of genetic contribution from high-risk and low-risk ancestral populations [11]. Recent successes in identifying susceptibility loci for type 2 diabetes provide the clearest arguments for the role of genes.

As with other complex traits, genetic predisposition is only part of the story: nongenetic (environmental) factors determine whether, and how, risk-associated genotypes lead to overt disease. Lifestyle-related factors such as physical activity levels and diet are, next to age, the most important determinants of the penetrance of a given set of diabetes-susceptibility genotypes. Thus, the prevalence of type 2 diabetes often increases dramatically when populations switch from rural and/or low risk dietary and physical activity patterns and adopt more urban, Western lifestyles [12, 13]. Physical activity has been shown to reduce insulin resistance [14] whereas a diet rich in fat and carbohydrate, but poor in fibre content, can aggravate it [15]. The consistent association between type 2 diabetes and measures of obesity, especially central obesity, almost certainly reflects common environmental as well as genetic factors underlying both conditions.

In recent years, a robust association between low birthweight and metabolic and cardiovascular disease 
(including type 2 diabetes) in adulthood has led to the hypothesis that suboptimal fetal nutrition represents an important environmental stimulus to future diabetes risk [16]. Though studies seeking direct support for this 'thrifty phenotype' mechanism in humans have proven inconclusive [17], the balance of evidence does favour the concept that lifelong metabolic 'programming' can be initiated in early life by the complex interaction of fetomaternal environment and fetal genotype. The plausibility of a genetic contribution to the observed association between fetal and adult phenotypes is enhanced by the realization that the genes expected to contribute to variation in fetal growth and survival (those involved in regulation of insulin action and secretion) are precisely the same genes implicated in the susceptibility to adult disease [18].

\section{On the trail of diabetes genes}

Several, complementary, approaches to disease gene identification are being actively pursued in the study of type 2 diabetes.

In some families, diabetes appears to be inherited as a monogenic trait, segregating in either classical Mendelian or maternal (mitochondrial) fashion. Autosomal dominant, early onset diabetes (known as maturity-onset diabetes of the young, MODY) has been revealed to be a genetically heterogeneous condition, with mutations in the glucokinase gene [19] and in genes for various transcription factors (hepatocyte nuclear factor (HNF) $-1 \alpha$ [20], HNF$1 \beta$ [21], HNF-4 $\alpha$ [22], insulin promotor factor 1 (IPF1) [23] and neurogenic differentiation 1 (NEUROD1) [24]), each capable of producing a phenotype in which beta-cell dysfunction predominates. In other families, diabetes results from defects in the insulin gene leading to mutant-insulin syndromes [25], and in the genes for the insulin receptor [26] and peroxisome proliferation-activated receptor gamma [27], producing extreme insulin-resistance. In yet other families, diabetes is one component of a broader syndrome (e.g. Wolfram syndrome, familial partial lipodystrophy [28]). The syndrome of maternally inherited diabetes with sensorineural deafness (MIDD) [29] results from a mutation in the mitochondrial tRNA ${ }^{\text {Leu(UUR) }}$ gene, at a site also implicated in a neurological condition named MELAS mitochondrial myopathy, encephalopathy, lactic acidosis and stroke-like episodes. By and large, studies of these genes in typical multifactorial type 2 diabetes, have not revealed them to be major players. However, there is no clear clinical demarcation between monogenic and multifactorial forms, and some genes (e.g. IPF1) seem capable of producing either phenotype [23, 30]. Such discoveries are providing crucial insights into the mechanisms responsible for the maintenance of normal glucose homeostasis. In particular, identification and characterization of the various MODY genes is shedding new light on the hidden inner workings of the beta-cell and the biochemical and transcriptional networks responsible for normal glucose-regulated insulin secretion.

The seminal studies on the ob/ob mouse demonstrate how rodent genetics can transform our understanding of human pathophysiology [31]. There are several rodent models of type 2 diabetes and related traits, but polygenic models such as the Goto-Kakizaki (GK) and Otsuka long Evans Tokushima fatty (OLETF) rats are likely to provide the most appropriate resources for identifying those genes relevant to human disease [32-34]. The GK rat, for example, shows, without evidence of overt obesity, the main metabolic, hormonal and vascular features described in human diabetes. Results from two independent studies have identified at least seven loci controlling diabetesrelated subphenotypes (mainly glucose intolerance, impairment of insulin secretion and adiposity/body weight) and emphasize the complex physiology (different loci seem to influence fasting and postload blood glucose) $[32,33]$. Though there is no guarantee that the genes causing diabetes in these polygenic rodent models are the same as those involved in human disease, these analyses (like those of human subtypes) provide examples of 'real' diabetes genes and clues to the key metabolic pathways responsible for the maintenance of normal glucose homeostasis. Similar insights are also likely to come through large-scale mutagenesis projects [35], and from transgenic manipulation of either single [36] or multiple [37] candidate genes.

Advances in our understanding of the physiology of nutrient regulation and of diabetes pathogenesis, generate a constantly expanding list of genes that, on the grounds of biology and/or implication in the development of human single-gene or rodent diabetes, are candidates for a role in typical multifactorial type 2 diabetes. The screening of these genes for nucleotide variants that are associated with type 2 diabetes is a core component of much diabetes genetics research. Such association analyses seek to demonstrate that a particular variant has higher than expected prevalence on 'disease-gene-carrying' chromosomes through, for example, comparison of genotype frequencies between groups of unrelated cases and control subjects. Because such studies rely on linkage disequilibrium for detection of a signal, positive results are only likely at, or very close to, functional variants. Association studies therefore provide a powerful approach for analysis of small regions, but remain problematical for screens of larger genomic regions. In type 2 diabetes, consistent susceptibility effects have only been identified at a small number of loci to date, including (arguably) the variable region upstream of the insulin gene (insulin variable number random repeat (INS-VNTR)) [38], and the genes for IPF-1 $[30,39]$, the sulphonylurea receptor 
[40, 41] and insulin-receptor substrate-1 [42]. This may, of course, mean that researchers have failed to study the 'right' candidates. However, there is no doubt that type 1 error, inadequate power, population stratification effects and the vagaries of linkage disequilibrium relationships in different populations have all contributed to the often contradictory results of such candidate gene studies [43]. A further limitation is that many studies have hitherto focused on coding regions, leaving regulatory gene sequences mostly unexplored. Given that so many of the MODY genes are involved in gene regulation, this may be a serious omission. It is clear that the revolution in the understanding of human genetic variation arising from the human genome project will, in the future, encourage more systematic and rational approaches to the evaluation of candidate loci for disease risk, characterized by large study populations, family-based association methods [43] and assessment of variation at the level of the haplotype rather than individual alleles.

All the methods described above make implicit assumptions about the likely biology of the genes contributing to multifactorial type 2 diabetes. In contrast, the genome-wide linkage approach attempts to locate such genes through their genomic position alone [43]. The rationale is straightforward: if family members share a given phenotype, they will also show excess sharing of chromosomal regions immediately surrounding genes contributing to that phenotype. Diabetes-susceptibility genes can therefore be revealed by finding regions of increased allele-sharing in collections of small multiplex families (typically affected sibpairs) [43]. This approach has been successfully applied to several complex inherited traits including type 1 diabetes, obesity, and psoriasis [44-46]. Because such studies depend on the detection of cosegregation within families (i.e. linkage) and, unlike association studies, do not require allele-specific effects (i.e. linkage disequilibrium), they are capable of detecting a signal over a wide area (10-30 centimorgan), thereby allowing analysis of the entire genome with only a few hundred polymorphic markers.

Around 25 genome-wide scans for type 2 diabetes are underway worldwide, involving over 5000 pedigrees from diverse ethnic groups [47-52]. The relatively low sibling relative risk for diabetes (about 3.5 fold increase compared with the general population [9]) sets a limit to the size of linkage signal that can be expected, and massive family collections and meticulous attention for detail are essential for success. In the UK, for example, the British Diabetic Association Warren 2 consortium is currently scanning over 1000 British type 2 diabetic sibpairs. These daunting experimental requirements have certainly slowed the delivery of results, but some consistent patterns can now be discerned through the fog of data [47-52]. It is clear that there is no single major gene of overwhelming importance in type 2 diabetes (nothing akin to HLA in type 1). However, several genomic regions (e.g. on chromosomes $1,7,11,12$ and 20) are showing interesting replications across datasets and thus represent foci for detailed exploration. New statistical methodologies (e.g. to exploit multilocus effects [53] and to analyse quantitative, as opposed to discrete, traits [54]) promise to permit us to squeeze more power from our existing studies.

Such genome-wide scans can identify regions of interest, but these may still contain up to 20 million base-pairs: finding the precise site(s) of aetiological variation within these regions represents a major challenge. Here, researchers stand to benefit from explosive technological developments (single nucleotide polymorphism (SNP) genotyping, proteomics, transcriptional profiling) and the burgeoning genomics databases (cataloguing human gene sequences, expression profiles and genomic variation) $[55,56]$. These enable a multifaceted attack which utilizes linkage disequilibrium mapping to refine disease gene location, together with bioinformatics and transcriptional profiling tools to pick out the regional genes with the strongest biological candidacy. These approaches are now bearing fruit, as amply demonstrated by the recent report implicating the calpain-10 gene as a major susceptibility gene in Mexican Americans [47, 57].

\section{The road ahead}

What can we infer from the current state of knowledge about the genetics of type 2 diabetes? It is clear that predictions of single major susceptibility genes were overly optimistic: individual susceptibility is almost certainly governed by the interaction of multiple genetic and environmental effects. There are good theoretical and biological reasons to believe that many of these susceptibility variants will be common polymorphisms in key regulatory genes [58]. As Neel pointed out several decades ago [59], genetic variants which today (given sedentary lifestyle and cafeteria diets) predispose to diabetes and obesity, might, in prehistoric times (when food supply was erratic) have been positively advantageous, and therefore maintained at high frequency. Whilst some of these diabetes-susceptibility variants might be very old indeed (predating the out-of-Africa expansion of modern humans) and contribute to disease worldwide, others may have become enriched in particular ethnic groups through interaction with specific environment, and/or genetic drift. Such effects may help to explain the marked ethnic differences in diabetes prevalence [1], and some of the difficulty replicating genome scan results across different populations [47-52]. In addition, there is an increasing suggestion that the seeds of adult diabetes are sown in early life. Recent data demonstrating parent-specific transmission effects at the insulin gene 
[38], together with the evidence for excess diabetes in the mothers of subjects with type 2 diabetes [60], and the known associations between foetal growth and adult disease [16], all suggest that susceptibility to adult diabetes may be initiated by genetic and environmental events operating in early life.

The spectacular advances in information and technology arising out of the Human Genome Project [55], combined with the massive clinical resources available to the research community and a spirit of international collaboration (exemplified by the efforts of the International Type 2 Diabetes Linkage Analysis Consortium, which acts as a forum for joint analysis of much of the world's type 2 diabetes genome scan data) provide a solid basis for future developments in this field. The expectation is that the coming decade will see the molecular basis of susceptibility to type 2 diabetes (and a host of other related conditions) laid bare.

Where will the genetic information take us? The hope is that it will inform future drug discovery programs and deliver targeted treatments that allow lifelong restoration of normal metabolic homeostasis. By identifying the pathways and tissues involved in the gradual metabolic decompensation that precedes full-blown diabetes, genetic studies should identify new therapeutic targets in fundamental pathways, and direct efforts to target therapies to relevant tissues. By allowing those individuals at greatest personal risk of future diabetes to be identified (on the basis of genotype as well as family history and environmental exposure), preventative measures and presymptomatic therapeutics can be targeted to those likely to benefit. By improving our nosological classification of type 2 diabetes and our understanding of pharmacogenetics, and thereby providing a sound basis for subdividing patients according to the predominant pathophysiological defect and predicted therapeutic response, rational individualized treatment selection becomes an achievable goal.

\section{References}

1 McCarty D, Zimmet P. Diabetes 1994-2010: global estimates and projections. Bayer AG, Leverkusen and International Diabetes Institute, Melbourne 1994.

2 King's Fund Policy Institute. Counting the cost: the real impact of non-insulin-dependent diabetes. British Diabetic Association, London, 1996.

3 McCarthy M, Hitman GA. The genetics of non-insulin dependent diabetes mellitus. In The causes of diabetes, ed. Leslie RDG. London: John Wiley, 1993: 157-183.

4 Reaven G. Role of insulin resistance in human disease. Diabetes 1988; 37: 1595-1607.

5 Zawalich WS, Kelley GG. The pathogenesis of NIDDM. The role of the pancreatic beta-cell. Diabetologia 1995; 38: 986-991.

6 UK Prospective Diabetes Study (UKPDS) Group. Intensive blood-glucose control with sulphonylureas or insulin compared with conventional treatment and risk of complications in patients with type 2 diabetes (UKPDS 33). Lancet 1998; 352: 837-853.

7 Barnett AH, Eff C, Leslie RDG, Pyke DA. Diabetes in identical twins: a study of 200 pairs. Diabetologia 1981; 20: 87-93.

8 Newman B, Selby JV, King MC, Slemenda C, Fabsitz R, Friedman GD. Concordance for type 2

(non-insulin-dependent) diabetes mellitus in male twins. Diabetologia 1987; 30: 763-768.

9 Köbberling J, Tillil H. Empirical risk figures for first degree relatives of non-insulin dependent diabetics. In The genetics of diabetes mellitus, eds. Köbberling J, Tattersall R. London: Academic Press, 1982: 201-209.

10 Zimmet P, Taylor R, Ram P, et al. The prevalence of diabetes and impaired glucose tolerance in the biracial (Melanesian and Indian) population of Fiji. A rural-urban comparison. Am J Epidemiol 1983; 118: 673-688.

11 Knowler WC, Pettitt DJ, Saad MF, Bennett PH. Diabetes mellitus in the Pima Indians: incidence, risk factors and pathogenesis. Diab/Metab Rev 1990; 6: 1-27.

12 Huang B, Rodriguez BL, Burchfield CM, Chyou PH, Curb JD, Yano K. Acculturation and prevalence of diabetes among Japanese-American men in Hawaii. Am J Epidemiol 1996; 144: 674-681.

13 Ostbye T, Welby TJ, Prior IA, Salmond CE, Stokes YM. Type 2 (non-insulin-dependent) diabetes mellitus, migration and westernisation: the Tokelau Island Migrant Study. Diabetologia 1989; 32: 585-590.

14 James DE, Kraegen EW, Chisholm DF. Effects of exercise training on in vivo insulin action in individual tissues in rat. J Clin Invest 1985; 76: 657-666.

15 Riccardi G, Rivellese A, Paioni D, Genovese S, Mastranzo P, Mancino N. Separate influence of dietary carbohydrate and fibre on the metabolic control in diabetes. Diabetologia 1984; 27: 116-121.

16 Barker DJP, Hales CN, Fall CHD, Osmond C, Phipps K, Clark PMS. Type 2 (non-insulin-dependent) diabetes mellitus, hypertension and hyperlipidaemia (syndrome $\mathrm{X}$ ): relation to reduced fetal growth. Diabetologia 1993; 36: 62-67.

17 Stanner SA, Bulmer K, Andrès C, et al. Does malnutrition in utero determine diabetes and coronary heart disease in adulthood? Results from the Leningrad siege study, a cross sectional study. Br Med J 1997; 315: 1342-1349.

18 Hattersley AT, Beards F, Ballantyne E, Appleton M, Harvey R, Ellard S. Mutations in the glucokinase gene of the foetus result in reduced birth weight. Nature Genet 1998; 19: 268-270.

19 Vionnet N, Stoffel M, Takeda J, et al. Nonsense mutation in the glucokinase gene causes early-onset non-insulin-dependent diabetes mellitus. Nature 1992; 356: 721-722.

20 Yamagata K, Oda N, Kaisaki PJ, et al. Mutations in the hepatocyte nuclear factor 1 a gene in maturity-onset diabetes of the young (MODY3). Nature 1996; 384: 455-458.

21 Horikawa Y, Iwasaki N, Hara M, et al. Mutation in hepatocyte nuclear factor-1 beta gene (TCF2) associated with MODY. Nature Genet 1997; 17: 384-385.

22 Yamagata K, Furuta H, Oda N, et al. Mutations in the hepatocyte nuclear factor 4 a gene in maturity-onset diabetes of the young (MODY1). Nature 1996; 384: 458-460.

23 Stoffers DA, Ferrer J, Clarke WL, Habener JF. Early-onset type-II diabetes mellitus (MODY4) linked to IPF1. Nature Genet 1997; 17: 138-139. 
24 Malecki MT, Jhala US, Antonellis A, et al. Mutations in NEUROD1 are associated with the development of type 2 diabetes mellitus. Nature Genet 1999; 23: 323-328.

25 Tager H, Given B, Baldwin D, et al. A structurally abnormal insulin causing human diabetes. Nature 1979; 281: $122-125$.

26 Kadowaki T, Bevins CL, Cama A, et al. Two mutant alleles of the insulin receptor gene in a patient with extreme insulin resistance. Science 1988; 240: 787-790.

27 Barroso I, Gurnell M, Crowley VE, et al. Dominant negative mutations in human PPARgamma associated with severe insulin resistance, diabetes mellitus and hypertension. Nature 1999; 402: 880-883.

28 Shackleton S, Lloyd DJ, Jackson SNJ, et al. LMNA, encoding lamin A/C, is mutated in partial lipodystrophy. Nature Genet 2000; 24: 153-156.

29 Kadowaki T, Kadowaki H, Mori Y et al. A subtype of diabetes mellitus associated with a mutation of mitochondrial DNA. N Engl J Med 1994; 330: 962-968.

30 Hani EH, Stoffers DA, Chevre JC, et al. Defective mutations in the insulin promoter factor-1 (IPF-1) gene in late-onset type 2 diabetes mellitus. J Clin Invest 1999; 104: R41-R48.

31 Zhang Y, Proenca R, Maffel M, Barone M, Leopold L, Friedman JM. Positional cloning of the mouse obese gene and its human homologue. Nature 1994; 372: 425-432.

32 Gauguier D, Froguel P, Parent V, et al. Chromosomal mapping of genetic loci associated with non-insulin dependent diabetes in the GK rat. Nature Genet 1996; 12: 38-43.

33 Galli J, Li LS, Glaser A, et al. Genetic analysis of non-insulin dependent diabetes mellitus in the GK rat. Nature Genet 1996; 12: 31-37.

34 Watanabe TK, Okuno S, Oga K, et al. Genetic dissection of 'OLETF', a rat model for non-insulin-dependent diabetes mellitus: quantitative trait locus analysis of $($ OLETF $\times$ BN $) \times$ OLETF. Genomics 1999; 58: 233-239.

35 Brown SDM, Nolan PM. Mouse mutagenesis - systematic studies of mammalian gene function. Hum Mol Genet 1998; 7: 1627-1633.

36 Withers DJ, Gutierrez JS, Towery H, et al. Disruption of IRS-2 causes type 2 diabetes in mice. Nature 1998; 391: 900-904.

37 Terauchi Y, Iwamoto K, Tamemoto H, et al. Development of non-insulin-dependent diabetes mellitus in the double knockout mice with disruption of insulin receptor substrate-1 and $\beta$ cell glucokinase genes. Genetic reconstruction of diabetes as a polygenic disease. J Clin Invest 1997; 99: 861-866.

38 Huxtable SJ, Saker PJ, Haddad L, et al. Analysis of parent-offspring trios provides evidence for linkage and association between the insulin gene and type 2 diabetes mediated exclusively through paternally transmitted class III variable number tandem repeat alleles. Diabetes 2000; 49: 126-130.

39 Macfarlane WM, Frayling TM, Ellard S, et al. Missense mutations in the insulin promoter factor-1 gene predispose to type 2 diabetes. J Clin Invest 1999; 104: R33-R39.

40 Inoue $\mathrm{H}$, Ferrer J, Welling CM, et al. Sequence variants in the sulfonylurea receptor (SUR) gene are associated with NIDDM in Caucasians. Diabetes 1996; 45: 825-831.

41 't Hart LM, de Knijff P, Dekker JM, et al. Variants in the sulphonylurea receptor gene: association of the exon 16-3t variant with Type II diabetes mellitus in Dutch Caucasians. Diabetologia 1999; 42: 617-620.

42 Almind K, Bjørbaek C, Vestergaard H, Hansen T, Echwald S, Pedersen O. Aminoacid polymorphisms of insulin receptor substrate-1 in non-insulin dependent diabetes mellitus. Lancet 1993; 342: 828-832.

43 Lander ES, Schork NJ. Genetic dissection of complex traits. Science 1994; 265: 2037-2048.

44 Davies JL, Kawaguchi Y, Bennett ST, et al. A genome-wide search for human type 1 diabetes susceptibility genes. Nature 1994; 371: 130-136.

45 Trembath R, Clough R, Rosbotham J, et al. Identification of a major susceptibility locus on chromosome $6 p$ and evidence for further disease loci revealed by a two stage genome-wide search in psoriasis. Hum Mol Genet 1997; 6: 813-820.

46 Norman RA, Tataranni PA, Pratley R, et al. Autosomal genomic scan for loci linked to obesity and energy metabolism in Pima Indians. Am J Hum Genet 1998; 62: 659-668.

47 Hanis CL, Boerwinkle E, Chakraborty R, et al. A genome-wide search for human non-insulin-dependent (type 2) diabetes genes reveals a major susceptibility locus on chromosome 2. Nat Genet 1996; 13: 161-171.

48 Elbein SC, Hoffman MD, Teng K, Leppert MF, Hasstedt SJ. A genome-wide search for type 2 diabetes susceptibility genes in Utah Caucasians. Diabetes 1999; 48: 1175-1182.

49 Pratley RE, Thompson DB, Bogardus C. An autosomal gene scan for loci linked to prediabetic phenotypes in Pima Indians. J Clin Invest 1998; 101: 1757-1764.

50 Stern M, Duggirala R, Mitchell B, et al. Evidence for linkage of regions on chromosomes 6 and 11 to plasma glucose concentrations in Mexican Americans. Genome Res 1996; 6: 724-734.

51 Mahtani MM, Widén E, Lehto M, et al. Mapping of a gene for NIDDM associated with an insulin secretion defect by a genome scan in Finnish families. Nature Genet 1996; 14: 90-95.

52 Ghosh S, Watanabe RM, Hauser ER, et al. Type 2 diabetes: evidence for linkage on chromosome 20 in 716 Finnish affected sib pairs. Proc Natl Acad Sci USA 1999; 96: 2198-2203.

53 Cox NJ, Frigge M, Nicolae DL, et al. Loci on chromosomes 2 (NIDDM1) and 15 interact to increase susceptibility to diabetes in Mexican Americans. Nat Genet 1999; 21: 213-215.

54 Almasy L, Blangero J. Multipoint quantitative-trait linkage analysis in general pedigrees. Am J Hum Genet 1998; 62: 1198-1211.

55 Collins FS, Patrinos A, Jordan E, et al. New goals for the US Human Genome Project: 1998-2003. Science 1998; 282: 682-689.

56 Lander ES. Array of hope. Nat Genet 1999; 21(Suppl): 3-4.

57 Horikawa Y, Oda N, Cox NJ, et al. Genetic variation in the gene encoding calpain-10 is associated with type 2 diabetes mellitus. Nature Genet 2000; 26: 163-175.

58 Cargill M, Altshuler D, Ireland J, et al. Characterization of single-nucleotide polymorphisms in coding regions of human genes. Nat Genet 1999; 22: 231-238.

59 Neel JV. The thrifty genotype revisited. In The genetics of diabetes mellitus, eds. Köbberling J, Tattersall R. London: Academic Press, 1982: 283-293.

60 Thomas F, Balkau B, Vauzelle-Kervroedan F, Papoz L, the Codiab-Inserm-Zeneca Study Group. Maternal effect and familial aggregation in NIDDM. The CODIAB Study. Diabetes 1994; 43: 63-67. 